\title{
Osteocutaneous flaps for head and neck reconstruction: A focused evaluation of donor site morbidity and patient reported outcome measures in different reconstruction options
}

\author{
Marie Kearns ${ }^{1,2}$, Panagiotis Ermogenous ${ }^{1,3}$, Simon Myers ${ }^{1}$, Ali Mahmoud Ghanem ${ }^{1}$ \\ ${ }^{1}$ Academic Plastic Surgery, Barts and the London School of Medicine and Dentistry, London; ${ }^{2}$ Canniesburn Plastic Surgery Unit, Glasgow \\ Royal Infirmary, Glasgow, UK; ${ }^{3}$ Department of Plastic and Reconstructive Surgery and Burns Unit, Nicosia General Hospital, Nicosia, Cyprus
}

With significant improvements in success rates for free flap reconstruction of the head and neck, attention has turned to donor site morbidity associated with osteocutaneous free flaps. In this review, we address the morbidity associated with harvest of the four most commonly used osteocutaneous flaps; the free fibula flap, the scapula flap, the iliac crest flap and the radial forearm flap. A comprehensive literature search was performed to identify articles relevant to donor site morbidity for these flaps. We assessed morbidity in terms of incidence of delayed healing, chronic pain, aesthetic outcomes, site specific complications and patient satisfaction/quality of life. Weighted means were calculated when sufficient studies were available for review. The radial forearm and free fibula flaps are associated with high rates of delayed healing of approximately $20 \%$ compared to the scapular $(<10 \%)$ and iliac flaps (5\%). The radial forearm flap has higher rates of chronic pain (16.7\%) and dissatisfaction with scar appearance (33\%). For the majority of these patients harvest of one of these four osteocutaneous does not limit daily function at long-term follow-up. The scapular osteocutaneous flap is associated with the lowest relative morbidity and should be strongly considered when the recipient defect allows. The radial forearm is associated with higher morbidity in terms of scarring, fractures, chronic pain and wrist function and should not be considered as first choice when other flap options are available.

Keywords Free tissue flaps / Mandibular reconstruction / Quality of life / Postoperative complications

\section{Correspondence:}

Ali Mahmoud Ghanem

Academic Plastic Surgery, Centre for

Cutaneous Research, Blizard Institute, Barts and the London School of

Medicine and Dentistry, 4 Newark St, London E1 2AT, UK

Tel: +44-20-7882-7173

Fax: +44-20-7882-2200

E-mail: a.ghanem@qmul.ac.uk

Received: 17 Oct 2017 • Revised: 7 Feb 2018 • Accepted: 15 Mar 2018

pISSN: 2234-6163 • elSSN: 2234-6171 • https://doi.org/10.5999/aps.2017.01592 • Arch Plast Surg 2018;45:495-503

\section{INTRODUCTION}

Osteocutaneous free flaps enable reconstruction of complex areas such as the mandible and midface following extensive oncological resections. Many procedures and techniques are possible and both the functional and aesthetic requirements of the reconstruction and any potential donor site morbidity must be carefully considered.

Patient reported outcome measures (PROMs) were developed as research tools aiming to understand the effects of a 
treatment or condition on patients' daily lives and to eliminate the gap between the patient's and the clinician's perception of a particular outcome. They are used by healthcare providers with the aim of improving the quality of care.

This review will focus on donor site morbidity associated with the four commonly performed osteocutaneous flaps for head and neck reconstruction; namely the free fibula flap, the scapular flap, iliac crest flap and the radial forearm flap with a particular focus on studies using PROMs.

\section{METHODS}

A PubMed search was performed using the terms "donor site morbidity," "patient reported outcomes," or "complications" with "free fibula flap," "scapular flap," "iliac crest flap," and "osteocutaneous radial forearm flap" from inception until September 2016. References from relevant papers were also reviewed. Studies were included which reported on donor site morbidity and PROMS following reconstruction with these four osteocutaneous flaps. Searches and studies for inclusion were reviewed independently by M.K. and P.E. Case reports and case series involving $<10$ patients were excluded.

\section{RESULTS}

The PubMed search returned 176 results and 64 studies were considered relevant and included in this review.

\section{Free fibula flap}

The use of the free fibula flap for mandibular reconstruction was first described by Hidalgo [1] in 1989 and has revolutionised mandibular reconstruction. It is considered to be the gold standard for reconstruction of segmental defects of the mandible and has a high success rate [2].

\section{Wound healing}

Ling and Peng [2] performed a systematic review of free fibula donor site morbidity with the calculation of weighted means. Early donor site complications such as infection and skin graft loss were seen in $9.9 \%$ of patients with primarily closed donor sites and $19 \%$ of patients with skin grafted donor sites. Of the patients who had skin grafts to their donor site $8.1 \%$ experienced partial graft loss and $4.7 \%$ experienced complete graft loss [2]. Zimmerman et al. [3] found that average time to donor site healing was 34 days (range, 14-60 days).

Although a trend can be seen towards less complications in wounds closed primarily, donor sites closed under tension may be prone to dehiscence and a pseudo-compartment syndrome [4]. Previous groups have recommended that donor sites with width of less than $4 \mathrm{~cm}$ can be closed safely without tension although this will vary with skin laxity $[5,6]$. Other techniques to reduce wound healing problems include using negative pressure wound therapy over skin grafts and the harvest of a fat-fascia only flap in order to enable primary closure $[7,8]$.

\section{Sensory deficit}

The common peroneal nerve is at risk of injury when raising this flap causing motor and sensory deficits. Twenty-one percent of patients report a sensory deficit and $10 \%$ complain of cold intolerance [2]. The incidence of objective sensory deficit was as high as $76 \%$ in some studies showing a marked discrepancy between patient reported and clinician reporting for this type of outcome [3].

\section{Table 1. Incidence of chronic pain post free fibula transfer}

\begin{tabular}{|llcll|}
\hline Author (year) & $\begin{array}{c}\text { Design } \\
\text { (level of evidence) }\end{array}$ & $\begin{array}{c}\text { No. of free } \\
\text { fibula flaps }\end{array}$ & Follow-up & Incidence chronic pain \\
\hline Akashi et al. 2016 [6] & Observational study (IV) & 35 & $17 \mathrm{mo}$ & $20 \%$ \\
Feuvrier et al. 2016 [9] & Observational study (IV) & 11 & $28 \mathrm{mo}$ & $73 \%$ (Constant 37\%, on exertion 27\%) \\
Li et al. 2014 [11] & Observational study (IV) & 45 & $48 \mathrm{mo}$ & $11 \%$ \\
Rendenbach et al. 2016 [10] & Cohort study (III) & 27 & $8 \mathrm{mo}$ & $51.4 \%$ Load dependent \\
Zavalishina et al. 2014 [12] & Observational study (IV) & 11 & $>1 \mathrm{yr}$ & $45 \%$ (Opiate requirement 9\%) \\
Ling et al. 2013 [13] & Observational study (IV) & 19 & $1-13 \mathrm{yr}$ & $31.6 \%$ (10.5\% Mild, 21\% severe-limits activities/opiate requirement) \\
Pototschnig et al. 2013 [14] & Observational study (IV) & 104 & $14 \mathrm{mo}$ & $8.7 \%$ Moderate pain \\
Papadopulos et al. 2008 [15] & Observational study (IV) & 23 & $1.3 \mathrm{yr}$ & $13 \%$ Mild pain \\
Farhadi et al. 2007 [17] & Observational study (IV) & 10 & $32.3 \mathrm{mo}$ & $30 \%$ Mild pain,10\% severe pain \\
Bodde et al. 2003 [16] & Observational study (IV) & 10 & $6-87 \mathrm{mo}$ & $60 \%$ \\
Zimmerman et al. 2001 [3] & Observational study (IV) & 42 & $34 \mathrm{mo}$ & $7 \%$ \\
Shindo et al. 2000 [4] & Retrospective study (IV) & 27 & $>3 \mathrm{mo}$ & $29.6 \%$ \\
Weighted mean & & & $21.1 \%$ \\
\hline
\end{tabular}




\section{Chronic pain}

Ling and Peng [2] found that $6.5 \%$ reported chronic pain (>3 months) at the donor site. However, a number of retrospective studies were included in this analysis which may have relied on the patient volunteering this information at routine follow-up and therefore underestimated the true incidence of chronic pain after free fibula transfer. Studies where PROMs were utilised and the patient asked specifically about pain are summarised in Table $1[3,4,6,9-17]$.

\section{Ankle function and gait}

Biomechanical studies have shown that patients walk at a slower speed and with shorter strides compared to controls $[9,16]$. Patient questionnaires reveal problems with ankle instability on uneven ground, climbing stairs, running and a feeling of weakness in the operated limb in some patients [3,5,6,9-11,13,1622]. Maciejewski and Szymczyk [19] found that problems climbing stairs were more common in females. Daniels et al. [23] utilized the lower limb component of the Musculoskeletal Outcomes Data Evaluation and Management System finding that $41 \%$ were dissatisfied with their ankle function at 3 years postoperatively.
The American Orthopaedic Foot and Ankle Society (AOFAS) Ankle-Hindfoot Scale is a 100-point outcome measure which includes questions about pain and function and objective measures of ankle stability, gait and range of motion [16]. The weighted mean of studies which assess the AOFAS score is 85.6 indicating good postoperative ankle function (Table 2) $[13,17$, 20,21,24-26]. Catala-Lehnen et al. [24] found significantly better AOFAS scores in those who had a fibula harvested with a medial approach compared to a lateral approach. Ling and Peng [2] found a $6.1 \%$ mean incidence of claw toe.

\section{Aesthetic outcomes}

Five studies were available for review where patients rated the outcomes for their donor site scar appearances. The rate of dissatisfaction with scar appearance ranged from $0 \%$ to $22.5 \%$ [12,13,15,27-29]. Sagalongos et al. [30] compared outcomes in patients who had a suprafascial or subfascial dissection using a patient questionnaire and found better contour and aesthetic outcomes for those who had undergone suprafascial dissection. Table 3 summarises the reports of aesthetic outcomes of free fibula flap donor site.

Table 2. AOFAS scores following free fibula transfer

\begin{tabular}{|c|c|c|c|c|}
\hline Author (year) & Design (level of evidence) & No. of patients & Follow-up ${ }^{\text {a) }}$ & AOFAS score \\
\hline Ling et al. 2013 [13] & Observational study (IV) & 19 & $1-13 y r$ & 96.89 \\
\hline Catala-Lehnen et al. 2012 [24] & Observational study (IV) & 39 & $81 \mathrm{mo}$ & 90.1 \\
\hline Sieg et al. 2010 [25] & Observational study (IV) & 57 & $27 \mathrm{mo}$ & 87 \\
\hline Farhadi et al. 2007 [17] & Observational study (IV) & 10 & $32.3 \mathrm{mo}$ & 87.3 \\
\hline Garrett et al. 2006 [20] & Observational study (IV) & 14 & - & 84.98 \\
\hline Mojallal et al. 2004 [21] & Observational study (IV) & 42 & $28 \mathrm{mo}$ & 93.7 \\
\hline Rogers et al. 2003 [26] & Observational study (IV) & 16 & $27 \mathrm{mo}$ & 77 \\
\hline Weighted mean & & & & 89.05 \\
\hline
\end{tabular}

Table 3. Aesthetic outcomes free fibula donor site

\begin{tabular}{|c|c|c|c|c|c|}
\hline Author (year) & $\begin{array}{c}\text { Design } \\
\text { (level of evidence) }\end{array}$ & $\begin{array}{l}\text { No. of } \\
\text { flaps }\end{array}$ & $\begin{array}{l}\text { Follow- } \\
\text { up }\end{array}$ & Assessment & Outcome \\
\hline Ling et al. 2013 [13] & Observational study (IV) & 19 & $1-13 \mathrm{yr}$ & $\begin{array}{l}\text { Point evaluation system (0-3), } \\
\text { Tang et al. } 1998 \text { [28] }\end{array}$ & Median score 0 (linear scar), range 0-2 \\
\hline Yilmaz et al. 2008 [27] & Observational study (IV) & 11 & $13 \mathrm{mo}$ & Self-rated donor site appearance & 45\% Excellent/good, 22.5\% acceptable, 22.5\% poor \\
\hline $\begin{array}{l}\text { Maciejewski and Szymczyk, } \\
2007 \text { [19] }\end{array}$ & Observational study (IV) & 54 & $63 \mathrm{mo}$ & Self-rated donor site appearance & $78 \%$ Good/very good, $17 \%$ moderate, $5 \%$ poor \\
\hline Bodde et al. 2003 [16] & Observational study (IV) & 10 & $6-87$ mo & Point evaluation system & $\begin{array}{l}\text { 50\% Excellent, } 20 \% \text { good, } 10 \% \text { moderate, } 10 \% \\
\text { intermediate, } 10 \% \text { bad }\end{array}$ \\
\hline Tang et al. 1998 [28] & Observational study (IV) & 39 & $59 \mathrm{mo}$ & Point evaluation system (0-3) & $\begin{array}{l}\text { 45\% Linear scar, 22\% minor (slight scar depression, } \\
\text { hidden), } 26 \% \text { moderate (spread scar skin graft), } 7 \% \\
\text { major (obvious disfigurement) }\end{array}$ \\
\hline Ferri et al. 1997 [29] & Observational study (IV) & 29 & $3 \mathrm{mo}$ & Patient reported outcomes & $13.8 \%$ Reported unsightly donor site \\
\hline
\end{tabular}


Quality of life

The Short Form-36 (SF-36) is a validated questionnaire which measures general health status and social functioning [23]. Daniels et al. [23] found no significant difference in SF-36 scores for free fibula patients and a control population. Other qualitative studies have found levels of anxiety related to free fibula donor sites with patients worried that the operated limb would be more prone to injury and as a consequence avoided certain activities [11]. Ling and Peng [2] found that 9.6\% of patients felt limited in their work.

\section{Scapular flap}

Scapular osteocutaneous free flaps have been more frequently used for head and neck reconstruction in recent years. Up to 8 $\mathrm{cm}$ of bone can be harvested using this flap and skin tends to be a good color match for the face. It is favoured in elderly patients due to the relative sparing from atherosclerosis noted in the circumflex scapular artery. The donor site can usually be closed primarily leaving an oblique or transverse scar on the back.

\section{Wound healing}

Early complications are minimal with rates of wound dehiscence reported at $0 \%$ to $10.5 \%$, delayed healing $0 \%$ to $10 \%$ and seroma $0 \%$ to $27 \%$ [31-35].

\section{Shoulder function}

The Disability of the Arm, Shoulder, and Hand (DASH) and Constant-Murley scores can be used to assess postoperative shoulder function. The DASH test is a subjective measure of patients' perceived morbidity whilst the Constant-Murley combines subjective and objective assessment of shoulder function $[33,36]$. Clark et al. [36] found a mean DASH score of 10.6 at 9 months postoperatively being comparable to the normal population. Ferrari et al. [31] found higher DASH scores with an average of 48.6. Patients report difficulty with heavy lifting although this does not limit their daily activities and DASH scores improve with time following the operation. Ferrari et al. [31] found a mean Constant-Murley score of 92.2 out of 100 whilst Bianchi et al. [37] found a mean score of 60.6 in an older series of patients (74.1 years vs. 57.6 years) $[33,38]$. Again, none of these patients were limited in activities of daily living [37].

Suturing of serratus anterior to the scapula and approximating the muscles of the rotator cuff with the arm abducted and the hand above the level of the head has been suggested to improve postoperative shoulder function [39].

No studies were found which assessed donor site appearance, quality of life or patient satisfaction following reconstruction with a scapular flap. The scar is placed in an inconspicuous place compared to fibula or radial forearm flaps and skin grafts are not usually required suggesting that aesthetic donor site morbidity from this scar could be minimal.

\section{Iliac crest flap}

The iliac crest free flap, based on the deep circumflex iliac artery (DCIA), provides another option for maxillary and mandibular reconstruction. It can be harvested as an osteocutaneous or osteomusculocutaneous flap with inclusion of external oblique muscle.

\section{Wound healing}

The iliac crest donor site can usually be closed primarily and early wound complications have been reported as low at an incidence of $0 \%$ to $5 \%[13,38]$.

\section{Sensory deficits}

The lateral cutaneous branch of iliohypogastric, ilioinguinal, and lateral femoral cutaneous nerves are at risk of injury at the time or raising the iliac crest flap $[13,38]$. Femoral nerve palsies have also been reported and are thought to be due to traction injuries caused by patient positioning [22,38]. Twenty-seven percent of patients report sensory changes related to the lateral femoral cutaneous nerve at long-term follow-up $[13,38]$. Three point six percent report cold intolerance [38]. Primary nerve repair at the time of surgery has been recommended to reduce sensory deficits.

\section{Chronic pain}

Three studies were available for review which analyzed the incidence if chronic pain after the DCIA flap and these are outlined in Table $4[22,38,40]$. Eight point four percent experienced pain

Table 4. Incidence of chronic pain post free iliac osteocutaneous flap transfer

\begin{tabular}{|lcccll|}
\hline Author (year) & Design (level of evidence) & No. of flaps & Follow-up & \multicolumn{1}{c|}{ Assessment } & Incidence chronic pain \\
\hline Valentini et al. 2009 [40] & Retrospective study (IV) & $31^{\text {a) }}$ & 6 mo-5 yr & Patient questionnaire & $26 \%$ Pain $>60$ day \\
Forrest et al. 1992 [38] & Retrospective study (IV) & 78 & $25 \mathrm{mo}$ & Patient interview & $8.4 \%$ Pain $>1 \mathrm{yr}, 6.1 \%$ tightness \\
Shpitzer et al. 1999 [22] & Observational study (IV) & 60 & $18 \mathrm{mo}$ & Chart review, clinical examination & $11.67 \%$ Persistent pain \\
\hline alPatients. & & & & \\
\hline
\end{tabular}


lasting more than 1 year [38]. No studies were available which assessed the severity of this pain or its effect on daily function.

\section{Hernia}

The incidence of hernia has been reported to be as high as $10 \%$ in some series $[13,22,27,38]$. The weighted mean of studies outlined in Table 5 is 5\%. Careful attention should be paid to donor site closure in order to prevent this complication, with a layered closure, permanent suture to the fascial layer and consideration of mesh insertion.

\section{Fracture}

Valentini et al. [40] reported a fracture incidence of $3 \%$.

\section{Aesthetic outcomes}

The iliac crest donor site can be closed primarily unless a large skin paddle is taken and leaves a scar which is usually hidden below the waist line. However, up to $20 \%$ of patients report a disfiguring scar $[38,40]$. When compared to the free fibula donor site the iliac crest flap is found to have better objective rating of the outcome, however subjective patients' evaluations were similar [13].

Loss of anatomic hip profile, which is associated with harvest of the anterior superior iliac spine (ASIS), was reported by Valentini et al. [40] in 39\% of patients and strengthens the argument for leaving the ASIS in place. The contour deformity is worse when a full thickness bone flap is taken.

\section{Gait}

Objective assessment following harvest of an iliac flap reveals an antalgic gait in approximately $25 \%$ of patients and reduced range of hip motion compared with the unoperated side $[13,38]$. The Harris Hip Score was designed for assessment of post-traumatic hip arthritis and assessed subjective and objective hip function. Ling et al. [13] found an average Harris Hip Score of 98.33 which is comparable with the normal population. Rogers et al. [26] found an average score of 88 which also indicates good hip function. Twenty-six percent of patients report difficulty with walking which lasts longer than 60 days [38]. Harvest of a split bone flap and aggressive postoperative physiotherapy are thought reduce potential gait disturbances.

\section{Quality of life}

Rogers et al. [26] assessed health related quality of life by administering the University of Washington Questionnaire which is specific to head and neck patients and the Hospital Anxiety and Depression Scale. They found that three quarters of patients rated their quality of life in the previous 7 days as good or better. They also found a correlation between poor scores in the Harris Hip Score and poor scores in the quality of life domain and high levels of pain and depression.

\section{Radial forearm osteocutaneous flap}

The radial forearm flap although more commonly used as a fasciocutaneous flap can also be harvested as an osteocutaneous flap for head and neck reconstruction.

\section{Wound healing}

Harvest of an osteocutaneous radial forearm flaps (OCRFF) will commonly leave a skin defect $>3 \mathrm{~cm}$ requiring a split thickness or full thickness skin graft for wound closure. Delayed healing and graft failure at the donor site can lead to exposure of the underlying flexor carpi radialis, palmaris longus or brachioradialis tendons or metalwork if internal fixation has been performed. Rates of wound breakdown and tendon exposure have been reported at $5 \%$ to $46 \%$ and metalwork exposure in $1 \%$ to $15 \%$ [ 41 44]. Bardsley et al. [45] found that in $18 \%$ patients who had an OCRFF wound healing was delayed for more than 10 weeks.

\section{Fracture}

Rates of radial fracture following OCRFF harvest range from $0 \%$ to $18 \%$ with rates in female patients being as high as $32 \%$ [ 42 44,46-50]. This means that the OCRFF is unsuitable for elderly patients or postmenopausal females. Measures to reduce the risk of fracture include harvesting a smaller bone segment, a boat shaped osteotomy, prophylactic internal fixation and post-

Table 5. Incidence of hernia post iliac flap harvest

\begin{tabular}{|lccccc|}
\hline Author (year) & Design (level of evidence) & No. of flaps & Follow-up & \multicolumn{1}{c|}{ Assessment } & Incidence hernia (\%) \\
\hline Ling et al. 2013 [13] & Observational study (IV) & 15 & $1-12 \mathrm{yr}$ & Clinical examination & 8.3 \\
Valentini et al. 2009 [40] & Retrospective study (IV) & 31 & $6-60 \mathrm{mo}$ & Patient questionnaire & 3.0 \\
Rogers et al. 2003 [26] & Observational study (IV) & 16 & 27 mo & Clinical examination & 0 \\
Shpitzer et al. 1999 [22] & Observational study (IV) & 60 & $18 \mathrm{mo}$ & Chart review, clinical examination & 3.3 \\
Forrest et al. 1992 [38] & Retrospective study (IV) & 82 & $25 \mathrm{mo}$ & Patient interview & 9.7 \\
Weighted mean & & & & & 5.9 \\
\hline
\end{tabular}


operative immobilisation [45].

\section{Sensory disturbance}

The superficial branch of the radial nerve is at risk when raising this flap which may lead to the development of a neuroma. Sinclair et al. [43] administered the DASH questionnaire and found that $10 \%$ reported a persistent and troublesome sensory disturbance at long-term follow-up. Richardson et al. [51] found a $14 \%$ incidence of cold intolerance in a mixed group of patients who had osteocutaneous and fasciocutaneous radial forearm flaps.

\section{Chronic pain}

Sinclair et al. [43] found that $16.7 \%$ had moderate to extreme pain at a mean of 35 months follow-up, $37 \%$ had pain when using the operated arm and 13\% experienced difficulty sleeping due to pain.

\section{Wrist function}

Two studies were found that used the DASH score to assess long-term functional morbidity. Sinclair et al. [43] found a mean score of 18.9 which was not statistically different from the DASH scores in a group who had a fasciocutaneous radial forearm flap (DASH score 11.2). Deleyiannis et al. [47] found a similar average DASH score of 16.7 , however one third of patients in this series reported disability secondary to harvest of the OCRFF. Some studies showed reduced grip strength and dexterity although these are limited as they compare function with the patient's dominant non-operated limb [26-28].

\section{Aesthetic appearance}

There are no studies looking at scar results from the OCRFF, however there is a number of studies where patients who had fasciocutaneous flaps rated the donor site appearance. One study found a $90 \%$ rate of satisfaction with their scar whilst other found that approximately one-third of patients were unhappy with their scar and felt self-conscious wearing short sleeves in public $[52,53]$. Bardsley et al. [45] found that the donor site appearance was less acceptable in female than male patients.

\section{Quality of life}

No studies were found that looked specifically at quality of life after harvest of an OCRFF. Sinclair et al. [43] found that 13\% felt less confident or capable because of their operated forearm.

\section{Summary}

With regards to the relative morbidity of these flaps the main factors to be considered are wound healing, loss of function, gait
Table 6. Comparison of donor site morbidity for osteocutaneous flaps in head and neck reconstruction

\begin{tabular}{lcccc|}
\hline Morbidity & $\begin{array}{c}\text { Free fibula } \\
\text { flap }\end{array}$ & $\begin{array}{c}\text { Scapular } \\
\text { flap }\end{array}$ & $\begin{array}{c}\text { Iliac crest } \\
\text { flap }\end{array}$ & $\begin{array}{c}\text { Radial } \\
\text { forearm } \\
\text { flap }\end{array}$ \\
\hline Delayed wound healing & ++ & - & - & ++ \\
Sensory abnormalities & + & - & + & + \\
Chronic pain & + & - & ++ & ++ \\
Upper limb disability & - & + & - & ++ \\
Gait problems & + & - & + & - \\
Scar & + & - & + & +++ \\
Fracture & - & - & + & +++ \\
Hernia & - & - & + & - \\
\hline
\end{tabular}

problems and aesthetic appearance. Sites which require skin grafting such as the free fibula and radial forearm flap can require prolonged periods to heal which impacts on the patient's quality of life, ability to undergo adjuvant treatment and an untoward aesthetic appearance. The relative morbidity of each of these flaps is summarised in Table 6 .

This review is limited by the paucity of comparative studies available in the literature. There is therefore some difficult in comparing donor site outcomes across various studies with unmatched populations and varying outcome criteria. In addition, donor site morbidity with each of these flaps will depend on the size of the flap harvested which is turn dictated by the reconstructive requirements at the resection site. Many surgeons will refine their management of the donor site and this may affect the overall aesthetic outcome and affect comparison between various studies. For example, using a sheet graft versus a mesh skin graft will give a different donor site appearance after radial forearm flap harvest.

Donor site morbidity is one important factor in choosing a reconstructive option for an individual patient however for mandibular reconstruction the flap chosen will be dictated by the bone defect being reconstructed. Radial forearm flaps and scapular flaps supply inferior bone when compared to DCIA and fibular flaps and does not tolerate osteotomies well [54]. Limitations with DCIA flap include the color match of groin and the bulkiness of its muscle cuff. The DCIA flap provides greater bone height compared to the fibular flap although this can be increased by using a double-barrelled flap.

\section{REDUCING DONOR SITE} MORBIDITY: FUTURE DIRECTIONS AND RESEARCH

\section{Modification/refinement of surgical technique}

Refinements of the radial forearm and free fibula flaps have been 
described to prevent the need for split thickness skin grafting including design of the skin paddle to facilitate primary closure and the use of local flaps $[55,56]$. Other measures such as limiting the bone harvested with a radial forearm flap to prevent fractures and careful layered closure and use of mesh with iliac flaps have been discussed earlier in this text.

\section{Minimally invasive surgery}

Endoscopic and robotic-assisted free flap harvested has been described for reconstruction of other areas. Lin et al. [57] compared endoscopic-assisted versus the traditional open technique for free latissimus dorsi (LD) flap harvested, finding reduced patient reported postoperative pain, better overall patient satisfaction and scar evaluation in the endoscopic-assisted group, allowing earlier and improved mobilization of the upper limb. Complication rates were similar in the two groups. Clemens et al. [58] reported good results with robotic-assisted LD harvest.

\section{Tissue engineering}

Future strategies include tissue engineering, utilizing scaffolds (ranging from collagen sponges to autologous autoclaved bone) combined with bone marrow derived stromal cells and growth factors [54].

\section{CONCLUSIONS}

In this review, we have assessed the donor site morbidity of 4 commonly used osteocutaneous flaps in head and neck reconstructions. The scapular osteocutaneous flap has the lowest relative donor site morbidity with the main finding being a mild reduction in shoulder function which does not impact on daily life. The free fibula whilst having frequent early problems with wound healing has minimal effect on function and quality of life at a long-term follow-up. The advantages of the iliac flap include a hidden scar, low incidence of wound healing problems and minimal effect on hip function, however it is associated with chronic pain and a contour deformity. The radial forearm flap stands out as the flap with lowest patient satisfaction, having a highly conspicuous scar, a high rate of wound healing complications and an unacceptable incidence of radial fracture in some series. Donor site morbidity must be balanced with the reconstructive requirements of the defect and it must be noted that these four flaps cannot be regarded as equal in this regard. However, when a flap with higher donor site morbidity is required, measures can also be taken in terms of refining surgical technique to reduce complications. Tissue engineering, three-dimensional printing and minimally invasive surgery all present exciting opportunities to prevent donor morbidity in the future.

\section{NOTE}

\section{Conflict of interest}

No potential conflict of interest relevant to this article was reported.

\section{REFERENCES}

1. Hidalgo DA. Fibula free flap: a new method of mandible reconstruction. Plast Reconstr Surg 1989;84:71-9.

2. Ling XF, Peng X. What is the price to pay for a free fibula flap? A systematic review of donor-site morbidity following free fibula flap surgery. Plast Reconstr Surg 2012;129:65774.

3. Zimmermann CE, Borner BI, Hasse A, et al. Donor site morbidity after microvascular fibula transfer. Clin Oral Investig 2001;5:214-9.

4. Shindo M, Fong BP, Funk GF, et al. The fibula osteocutaneous flap in head and neck reconstruction: a critical evaluation of donor site morbidity. Arch Otolaryngol Head Neck Surg 2000;126:1467-72.

5. Momoh AO, Yu P, Skoracki RJ, et al. A prospective cohort study of fibula free flap donor-site morbidity in 157 consecutive patients. Plast Reconstr Surg 2011;128:714-20.

6. Akashi M, Hashikawa K, Takasu H, et al. Comparison between primary closure and skin grafts of the free fibula osteocutaneous flap donor site. Oral Maxillofac Surg 2016;20: 233-7.

7. Bach CA, Guillere L, Yildiz S, et al. Comparison of negative pressure wound therapy and conventional dressing methods for fibula free flap donor site management in patients with head and neck cancer. Head Neck 2016;38:696-9.

8. Mohindra A, Parmar S, Praveen P, et al. The fat-fascia paddle only with a composite fibula flap: marked reduction in donor site morbidity. Int J Oral Maxillofac Surg 2016;45:964-8.

9. Feuvrier D, Sagawa Y Jr, Beliard S, et al. Long-term donorsite morbidity after vascularized free fibula flap harvesting: clinical and gait analysis. J Plast Reconstr Aesthet Surg 2016; 69:262-9.

10. Rendenbach C, Kohlmeier C, Suling A, et al. Prospective biomechanical analysis of donor-site morbidity after fibula free flap. J Craniomaxillofac Surg 2016;44:155-9.

11. Li X, Zhu K, Liu F, et al. Assessment of quality of life in giant ameloblastoma adolescent patients who have had mandible defects reconstructed with a free fibula flap. World J Surg Oncol 2014;12:201.

12. Zavalishina L, Karra N, Zaid WS, et al. Quality of life assessment in patients after mandibular resection and free fibula 
flap reconstruction. J Oral Maxillofac Surg 2014;72:161626.

13. Ling XF, Peng X, Samman N. Donor-site morbidity of free fibula and DCIA flaps. J Oral Maxillofac Surg 2013;71:160412.

14. Pototschnig H, Schaff J, Kovacs L, et al. The free osteofasciocutaneous fibula flap: clinical applications and surgical considerations. Injury 2013;44:366-9.

15. Papadopulos NA, Schaff J, Sader R, et al. Mandibular reconstruction with free osteofasciocutaneous fibula flap: a 10 years experience. Injury 2008;39 Suppl 3:S75-82.

16. Bodde EW, de Visser E, Duysens JE, et al. Donor-site morbidity after free vascularized autogenous fibular transfer: subjective and quantitative analyses. Plast Reconstr Surg 2003;111:2237-42.

17. Farhadi J, Valderrabano V, Kunz C, et al. Free fibula donorsite morbidity: clinical and biomechanical analysis. Ann Plast Surg 2007;58:405-10.

18. Yang W, Zhao S, Liu F, et al. Health-related quality of life after mandibular resection for oral cancer: reconstruction with free fibula flap. Med Oral Patol Oral Cir Bucal 2014;19:e414-8.

19. Maciejewski A, Szymczyk C. Fibula free flap for mandible reconstruction: analysis of 30 consecutive cases and quality of life evaluation. J Reconstr Microsurg 2007;23:1-10.

20. Garrett A, Ducic Y, Athre RS, et al. Evaluation of fibula free flap donor site morbidity. Am J Otolaryngol 2006;27:29-32.

21. Mojallal A, Besse JL, Breton P. Donor site morbidity after free fibula flap: report of 42 consecutive cases. Ann Chir Plast Esthet 2004;49:3-10.

22. Shpitzer T, Neligan PC, Gullane PJ, et al. The free iliac crest and fibula flaps in vascularized oromandibular reconstruction: comparison and long-term evaluation. Head Neck 1999;21:639-47.

23. Daniels TR, Thomas R, Bell TH, et al. Functional outcome of the foot and ankle after free fibular graft. Foot Ankle Int 2005;26:597-601.

24. Catala-Lehnen P, Rendenbach C, Heiland M, et al. Longterm donor-site morbidity after microsurgical fibular graft: is there a difference between the medial approach and the lateral approach? J Oral Maxillofac Surg 2012;70:2198-204.

25. Sieg P, Taner C, Hakim SG, et al. Long-term evaluation of donor site morbidity after free fibula transfer. Br J Oral Maxillofac Surg 2010;48:267-70.

26. Rogers SN, Lakshmiah SR, Narayan B, et al. A comparison of the long-term morbidity following deep circumflex iliac and fibula free flaps for reconstruction following head and neck cancer. Plast Reconstr Surg 2003;112:1517-25.

27. Yilmaz M, Vayvada H, Menderes A, et al. A comparison of vascularized fibular flap and iliac crest flap for mandibular reconstruction. J Craniofac Surg 2008; 19:227-34.

28. Tang CL, Mahoney JL, McKee MD, et al. Donor site morbidity following vascularized fibular grafting. Microsurgery 1998;18:383-6.

29. Ferri J, Piot B, Ruhin B, et al. Advantages and limitations of the fibula free flap in mandibular reconstruction. J Oral Maxillofac Surg 1997;55:440-8.

30. Sagalongos OS, Valerio IL, Hsieh CH, et al. Qualitative and quantitative analyses of donor-site morbidity following suprafascial versus subfascial free fibula flap harvesting. Plast Reconstr Surg 2011;128:137-45.

31. Ferrari S, Ferri A, Bianchi B, et al. Donor site morbidity after scapular tip free flaps in head-and-neck reconstruction. Microsurgery 2015;35:447-50.

32. Mitsimponas KT, Iliopoulos C, Stockmann P, et al. The free scapular/parascapular flap as a reliable method of reconstruction in the head and neck region: a retrospective analysis of 130 reconstructions performed over a period of 5 years in a single department. J Craniomaxillofac Surg 2014; 42:536-43.

33. Choi N, Cho JK, Jang JY, et al. Scapular tip free flap for head and neck reconstruction. Clin Exp Otorhinolaryngol 2015; $8: 422-9$.

34. Dowthwaite SA, Theurer J, Belzile M, et al. Comparison of fibular and scapular osseous free flaps for oromandibular reconstruction: a patient-centered approach to flap selection. JAMA Otolaryngol Head Neck Surg 2013;139:285-92.

35. Kalavrezos N, Hardee PS, Hutchison IL. Reconstruction of through-and-through osteocutaneous defects of the mouth and face with subscapular system flaps. Ann R Coll Surg Engl 2005;87:45-52.

36. Clark JR, Vesely M, Gilbert R. Scapular angle osteomyogenous flap in postmaxillectomy reconstruction: defect, reconstruction, shoulder function, and harvest technique. Head Neck 2008;30:10-20.

37. Bianchi B, Ferri A, Ferrari S, et al. Reconstruction of mandibular defects using the scapular tip free flap. Microsurgery 2015;35:101-6.

38. Forrest C, Boyd B, Manktelow R, et al. The free vascularised iliac crest tissue transfer: donor site complications associated with eighty-two cases. Br J Plast Surg 1992;45:89-93.

39. Piazza C, Paderno A, Taglietti V, et al. Evolution of complex palatomaxillary reconstructions: the scapular angle osteomuscular free flap. Curr Opin Otolaryngol Head Neck Surg 2013;21:95-103.

40. Valentini V, Gennaro P, Aboh IV, et al. Iliac crest flap: donor site morbidity.J Craniofac Surg 2009;20:1052-5. 
41. Arganbright JM, Tsue TT, Girod DA, et al. Outcomes of the osteocutaneous radial forearm free flap for mandibular reconstruction. JAMA Otolaryngol Head Neck Surg 2013; 139:168-72.

42. Shnayder Y, Tsue TT, Toby EB, et al. Safe osteocutaneous radial forearm flap harvest with prophylactic internal fixation. Craniomaxillofac Trauma Reconstr 2011;4:129-36.

43. Sinclair CF, Gleysteen JP, Zimmermann TM, et al. Assessment of donor site morbidity for free radial forearm osteocutaneous flaps. Microsurgery 2012;32:255-60.

44. Werle AH, Tsue TT, Toby EB, et al. Osteocutaneous radial forearm free flap: its use without significant donor site morbidity. Otolaryngol Head Neck Surg 2000;123:711-7.

45. Bardsley AF, Soutar DS, Elliot D, et al. Reducing morbidity in the radial forearm flap donor site. Plast Reconstr Surg 1990;86:287-92.

46. Clark S, Greenwood M, Banks RJ, et al. Fracture of the radial donor site after composite free flap harvest: a ten-year review. Surgeon 2004;2:281-6.

47. Deleyiannis FW, Sacks JM, McLean KM, et al. Patient selfreport of disability of the upper extremity following osteocutaneous radial forearm free flap harvest. Plast Reconstr Surg 2008;122:1479-84.

48. Villaret DB, Futran NA. The indications and outcomes in the use of osteocutaneous radial forearm free flap. Head Neck 2003;25:475-81.

49. Thoma A, Khadaroo R, Grigenas O, et al. Oromandibular reconstruction with the radial-forearm osteocutaneous flap: experience with 60 consecutive cases. Plast Reconstr Surg 1999;104:368-78.
50. Zenn MR, Hidalgo DA, Cordeiro PG, et al. Current role of the radial forearm free flap in mandibular reconstruction. Plast Reconstr Surg 1997;99:1012-7.

51. Richardson D, Fisher SE, Vaughan ED, et al. Radial forearm flap donor-site complications and morbidity: a prospective study. Plast Reconstr Surg 1997;99:109-15.

52. Toschka H, Feifel H, Erli HJ, et al. Aesthetic and functional results of harvesting radial forearm flap, especially with regard to hand function. Int J Oral Maxillofac Surg 2001;30: 42-8.

53. Lee JH, Alrashdan MS, Kim SG, et al. Functional and esthetic assessment of radial forearm flap donor site repaired with split thickness skin graft. Eur Arch Otorhinolaryngol 2011;268:109-15.

54. Chim H, Salgado CJ, Mardini S, et al. Reconstruction of mandibular defects. Semin Plast Surg 2010;24:188-97.

55. Garg RK, Wieland AM, Poore SO, et al. The radial forearm snake flap: a novel approach to oral cavity and oropharyngeal reconstruction that reduces forearm donor site morbidity. Microsurgery 2017;37:6-11.

56. Sharma M, Balasubramanian D, Thankappan K, et al. Propeller flaps in the closure of free fibula flap donor site skin defects. Ann Plast Surg 2013;71:76-9.

57. Lin CH, Wei FC, Levin LS, et al. Donor-site morbidity comparison between endoscopically assisted and traditional harvest of free latissimus dorsi muscle flap. Plast Reconstr Surg 1999; 104:1070-7.

58. Clemens MW, Kronowitz S, Selber JC. Robotic-assisted latissimus dorsi harvest in delayed-immediate breast reconstruction. Semin Plast Surg 2014;28:20-5. 